\title{
Shipwrecked with John Rawls: \\ Decision Making behind a Veil of Ignorance \\ in a Classroom Simulation
}

\author{
Greg M. Shaw \\ Department of Political Science \\ Illinois Wesleyan University \\ gshaw@iwu.edu \\ 309-556-3658
}

\begin{abstract}
In a classroom simulation that asks students to allocate scarce resources among a group of varied characters, evidence shows that ignorance of one's character assignment is strongly associated with a more Rawlsian pattern of distribution. When students do not know which character is their own, they tend to support the most vulnerable as they redistribute resources to ensure that nearly all of the characters can survive and thrive. This is particularly the case when students know that a small portion of their grade is determined by the fate of their character. In contrast, a control group of students who worked through the simulation without consequence for their grades were significantly less redistributive and were more willing to sacrifice weak characters. Implications of students' choices in the simulation segue nicely with class discussions of American social policy.
\end{abstract}

Prepared for presentation at the American Political Science Association's Teaching and Learning Conference, Albuquerque, New Mexico, February 2020

Acknowledgements: I remain in the debt of the many students who have participated in this simulation over the past several years, for their time and their thoughtful commentary on the project. I am particularly grateful to Jim Simone, William Munro, Kayley Rettberg, and Madi Cori for helpful conversations about this paper. Any shortcomings are my own. 


\section{Introduction}

Just as knowledge of one's own situation powerfully conditions one's stated preferences for public policy, self-knowledge also has implications for students in the classroom. John Rawls' (1971, 1993, 2001) proposition about how rational individuals would create societal rules from behind a veil of ignorance offers what is probably the most famous modern assessment of principles of distributive justice and what self-knowledge has to do with this. A key assumption for Rawls is that individuals situated this way and imbued with a sense of self-interest would select rules guiding society's distribution of resources that elevate the floor for its least well off members. Whether the original position with its veil of ignorance would in fact produce such a series of choices to achieve justice as fairness and whether Rawls' emphasis on primary goods is ideal are indeed deep-water controversies, and far more than this short paper seeks resolve (for theoretical arguments, see Nozick 1974, Wolff 1977, Sandel 1998, Walzer 1983, Okin 1989, Kukathas and Pettit 1990, Sen 1992; for empirical assessments, see Frohlich et al. 1987, Bond and Park 1991, and Chan 2005). However, asking undergraduates to wrestle with one part of this puzzle in earnest produces valuable pedagogical outcomes, including an appreciation for how knowledge of their own skills, resources, deficits, and points of privilege heavily conditions their own and their peers' assessments of how social goods should be shared, along with the notions of just deserts and social contracts more generally.

This paper reports the results of a multi-year classroom project in which undergraduates have faced an assignment that pushes them to engage in introspection on how they are to treat the strong and the weak in a small hypothetical society under stress. The results mostly support Rawls' assertions that actors behind a veil of ignorance would agree to a society arranged to foster significant support extended to the less-advantaged members, though not necessarily all of the least well off. The outcomes of this teaching simulation also demonstrate the possibility that college students can indeed begin to unpack how self-knowledge heavily conditions their own outlook on the world, and how intentionally created ignorance of it leads them to make very different decisions than they otherwise would. This simulation serves as a preface for later classroom conversations about redistributive policy in the American context and invites students to compare and contrast their choices on a metaphorical desert island with their choices regarding welfare, health care, Social Security and other public policies. 
For the past several years the students in my course on American social policy have begun the semester by working through a simulation I wrote that asks them to create a sensible division of resources among a cast of characters who have been metaphorically shipwrecked on a desert island. The group consists of 16 characters who range from strong and socially attractive, to moderately useful, to pitiable, to annoying, to potentially threatening. The strong and skilled characters can meet their basic needs efficiently enough that they have hours each day remaining to dedicate toward building a boat that can be used by them and potentially others to sail to safety. In contrast, most of the characters need all of their waking hours simply to meet their basic survival needs, thus they have little or no time to spare for boat building. The simulation asks students to play the role of an authoritative allocator of spare work hours and rule maker more generally, enabling them to decide how the group's spare work hours are divided. They may decide to banish or neglect characters if they wish, though the simulation does not explicitly encourage this behavior. Students understand that their grade on this assignment is directly related to how quickly their character can accumulate 200 hours of boat-building work. The more days this task takes to complete, the lower their grade. A speedy departure from the island can earn a student up to $105 \%$ on the assignment. Death of one's character results in a zero. The assignment is worth $3 \%$ of the overall course grade.

\section{Overview of the Simulation}

Prior to the beginning of the semester, students are randomly assigned to character roles. On the first day of class I introduce the simulation and offer a brief overview of the students' situation, the important task of building a boat, and how the scoring works. I also encourage them to read Michael Sandel's summary of Rawls' famous thought experiment (Sandel 2009). (Anecdotally, most of them don't seem to read this prior to completing the simulation. Shocking, I know.) Over the next couple of days, students read a fairly detailed description of the desert island situation and biographical sketches of each character, excerpts of which appear in the appendix of this paper. Students face the prospect of making decisions potentially based on a wide variety of considerations involving the characters' personalities, skills, demographic characteristics, interpersonal relationships, etc. They understand that a small percentage of their grade depends on the speediness of accumulating enough hours of work on the boat - either 
through their own efforts or donated by others - in order to leave the island. They also understand that they, as authoritative allocators of spare work hours, must put their decisions in writing. Once students turn in their decisions I reveal the list of characters with students' identities connected to them. We then have a discussion about their particular decisions, the overall pattern of decisions in the current class, and they are able to see the patterns of other groups' decisions from earlier semesters.

One strategy in the simulation would be to share the available work hours in ways that approximately equalize all of the 16 characters' progress on the boat-building project. This ensures a grade of $90 \%$ on the assignment, and students can see this based on a chart in the simulation document. (This chart is reproduced in the appendix to this paper.) However, this allocation would involve giving a disproportionate number of hours to two helpless children who need extra hours of care each day merely to survive. Given this, a variation on this equal-workaccumulation strategy would be to withhold help from these helpless children, share equally among the remaining characters, and take the chance that one is not assigned to either of these child characters. In actual practice, this narrowly targeted withholding of help sometimes leads to tragic results. It is not uncommon for a typical class to include one or two students who banish or severely neglect the character that turns out - by random chance - to be their own. Regret usually ensues.

The group conversation typically proceeds as follows: I reveal the identities of the students and their randomly assigned characters. There is an audible mix of sighs of relief and groans of misery. We then discuss the decisions students made, why they made these decisions, and how they feel about it. Objections usually cluster into a few categories, discussed below. Most commonly, students object that this make-believe desert island is not enough like the "real world" and that a more realistic setting (whatever that would be, something that students usually leave ill-defined) would have led them to make different decisions. I point out that $3 \%$ of their grade feels real to me. Most students acknowledge the insight that ignorance of one's resources, needs, and general situation goes a long way toward shaping their selection of - if not necessarily their preferences for - societal rules. Of course, whether or not the castaways, ignorant of their individual identities, have concrete preferences for distributional rules is, of course, a more complicated matter (Elster 1983). We revisit these findings many times over the 
course of the following weeks when welfare, health care, Social Security policy, the Earned Income Tax Credit, and affirmative action are on the syllabus.

The overall pattern of decisions shows that most students basically approximate what Rawls thought they would do, with a couple of exceptions. Specifically, they generally look out for the vulnerable characters and ensure at least a minimal level of support for nearly all of them, even though this is costly to the group. Whether or not students thoroughly internalize Rawls' perspective on distributive justice and social contracts in a normative way is beyond the scope of this project. However, the evidence is clear that most students behave in a mostly risk-averse manner, realizing they can still earn a $90 \%$ on the assignment while simultaneously protecting the weakest of the shipwrecked characters. ${ }^{1}$ Considering that this simulation occurs during the first week of class, and that it represents minimal study, this grade of an A-minus probably seems to the students like an easy pickup. Students who instead allocate more hours to the character that - again, by random chance - turns out to be their own can earn a grade as high as $105 \%$. However, betting this way on the right character - a 1 in 16 chance - is not common. This is to say that very few students pursue the strategy of piling up spare work hours on only a few characters in an effort to earn the highest possible grade.

For many students, their decision to share resources widely in the desert island simulation contrasts with their expressed preferences on the redistributive policies, discussions of which make up most of the rest of the course. When the conversation later turns to actual social policies, many students find themselves articulating opinions on these topics contra the kind of sharing they engaged in on the desert island. Reminding them of this conflict generates thoughtprovoking conversations. Many students grasp and internalize the lesson about how selfknowledge drives policy choices, while others - usually the free-market-oriented ones - resist this cognitive dissonance, and some of them critique me for being what they say is too politically liberal. In any case, the classroom conversations are worthwhile.

\footnotetext{
${ }^{1}$ There may, arguably, be a difference between being risk-averse and being Rawlsian. The former points to selfinterest; the latter would be wrapped up in the normative language of concerns about justice as fairness. It seems clear that the behaviors in this simulation flowing from these two motivations are observational equivalents. In fact, some other commentators have explicitly equated Rawls' position with risk-aversion. Since this project is less about empirically testing Rawls and more about demonstrating to students how self-knowledge affects their stated policy preferences, for present purposes I will not attempt to settle what might be a debate on this point.
} 
Beyond the insights about students' notions of justice as fairness, this simulation also serves as an ice-breaker, encouraging students to talk with each other and to share parts of their moral makeup early in the semester. Even if they publicly confess to throwing one or more of the cast-aways off a cliff, students are forgiving enough that this does not poison their relationships, since they are all, so to speak, in the same boat.

Although the main point of this paper is not to empirically test Rawls' argument about behavior from behind a veil of ignorance, others have undertaken this task. It is worthwhile to at least briefly consider their results. In a 1987 paper, Frohlich et al. reported a money-sharing experiment in which small groups of college students in Canada and the U.S. were asked to discuss and come to consensus on how to divide funds among characters whose individual identities the students did not know. The veil of ignorance motivated the small groups to reach consensus, though the content of those group decisions varied significantly. Some groups sought principally to elevate the floor for the poorest people, though more groups pursued a strategy of maximizing the average while only secondarily putting in place a constraint on the floor, preventing it from falling far below the mean. In this sense, by not elevating the floor in a concerted way the participants did not particularly enact the difference principle. Using a different research design, this one employing a long series of questions about how characters should be treated, Bond and Park (1991) found support for elevating the floor, though not strong support for maximizing the average by capping the upper utility limit (that is, they did not tend to endorse a Robin Hood strategy). Because of different research strategies, these two studies are difficult to directly compare, though both found mixed evidence that simulation participants often considered the importance of elevating the floor for poorly resourced persons even if they did not make that their primary strategy. Chan (2005), in studies involving Chinese subjects, found similar patterns of not strongly relying on a strategy of maximizing the floor for the least well off. It turns out that my students tended to support the least well off somewhat more broadly than did subjects in these other research projects.

\section{A Closer Look at the Characters and Students' Decision Strategies}

In order to create a diversity of bases for students' decisions, the simulation goes into more detail about the castaways' situation than is, strictly speaking, necessary. Each character is 
named in a bluntly descriptive way (the Slacker, the Over-Achiever, the Handicapped Person, the Orphan Girl, etc.). Characters' background sketches paint pictures in colorful ways that invite students to develop an affinity - or not - with characters such as the Stow-Away Kid, the Athlete, or the Philosopher. (Readers will likely find it useful to review these descriptions in the appendix before proceeding with the rest of the paper.) Students might, for instance, opt to help the Philosopher, even though he is more or less dead-weight when it comes to boat building. The attraction is often that the Philosopher can speak Navajo with the Stranger, who speaks only Navajo. Alternatively, students can strip down the decision rules to focusing exclusively on how quickly every character can accumulate the required number of boat-building hours. The characters range from strong and smart to threatening. The Single Father has a demonstrated record of anti-sociability and is in possession of a private stash of heroin. He is one of the least sympathetic characters in the group, and students withhold help from him more often than from nearly any other character. The island setting and some valuable skills are also identified: swimming, tree climbing, water carrying, etc. Most of the characters have explicitly limited skill sets.

Each character is designated as having a fixed number of extra work hours available per day, after meeting basic survival needs plus seven hours of sleep. Five of the characters have spare hours that can be spent on boat building. These strong characters may be compelled to share these work hours with others, or their hours may instead be assigned to themselves, or any combination of these. Nine characters have no spare work hours to offer, meaning they can meet their own survival needs but cannot earn a place on the boat by working to build it. Lastly, two of the characters are in a deficit situation, needing five hours of help each day merely to survive. Helping these two young children is costly for the group. Collectively, the group has 29 spare person-hours per day to work on the boat. For a character to merely survive without accumulating the requisite boat-building hours translates to a grade of $20 \%$ on this assignment. The simulation is intentionally complex, listing various specific tasks that may come in handy. This serves to allow students to base their decisions on many different dimensions beyond simply the number of hours a character needs to secure a place on the boat. Some students wade deeply into these details, while most do not. 
While the decisions about the number of hours to share are central to determining how each student values each character, the simulation also asks students to report their subjective evaluation of each character by rating him or her on their "overall value to the group," using a 110 scale. These scores, while non-binding, offer a quantitative reference point to which the number of work hours allocated can be compared. As one would suspect with such a varied group of characters, these subjective evaluation scores are widely spread. The extent to which the subjective valuations correlate with the number of hours of boat work shared with each character is discussed below.

Cognizant that having a grade at stake may change how risk-averse students are when working through this simulation, I have enlisted several other classes to respond to the simulation, extending a small amount of extra credit for completing it but not assigning any grade based on how students allocate resources. The comparisons across these two groups are reported below. The analysis below pools data across 14 class sections, spanning seven years, and including 230 students. The larger portion of participants, 177 students, competed this simulation where they had a grade at stake in an American Social Policy class. A smaller number, 53, were from other classes where no grade was at stake. Of those participants who indicated their gender, 113 of them were males and 92 were female. The students are mostly sophomores and juniors and vary widely in their major fields of study.

\section{Overall Results and the Difference a Grade Makes}

Figure 1 shows the average value assigned to each of the 16 characters, and error bars indicate one standard deviation around the mean. ${ }^{2}$ This display is based on all respondents, whether or not the students had a grade at stake. As it turns out, whether or not students were performing this simulation for a grade or not made a difference in the subjective valuation for only five of the characters: the Slacker, Chaplain, Stranger, Artist, and Orphan Girl. In each instance of a difference, students with a grade at stake assigned a higher value than did the students in the non-graded condition. Across all 16 characters, these value scores vary a great deal. The Over-Achiever, Athlete, and Hustler score on average near or above 8 on the 1-10 scale, and the helpless children scoring below 2. Clearly, regardless of the strategies the students

\footnotetext{
${ }^{2}$ All quantitative analysis performed using version 25 of SPSS
} 
subsequently pursued, they were able to discriminate dramatically among these characters. Again, how they scored the characters on this valuing exercise was of no consequence to their success in the simulation.

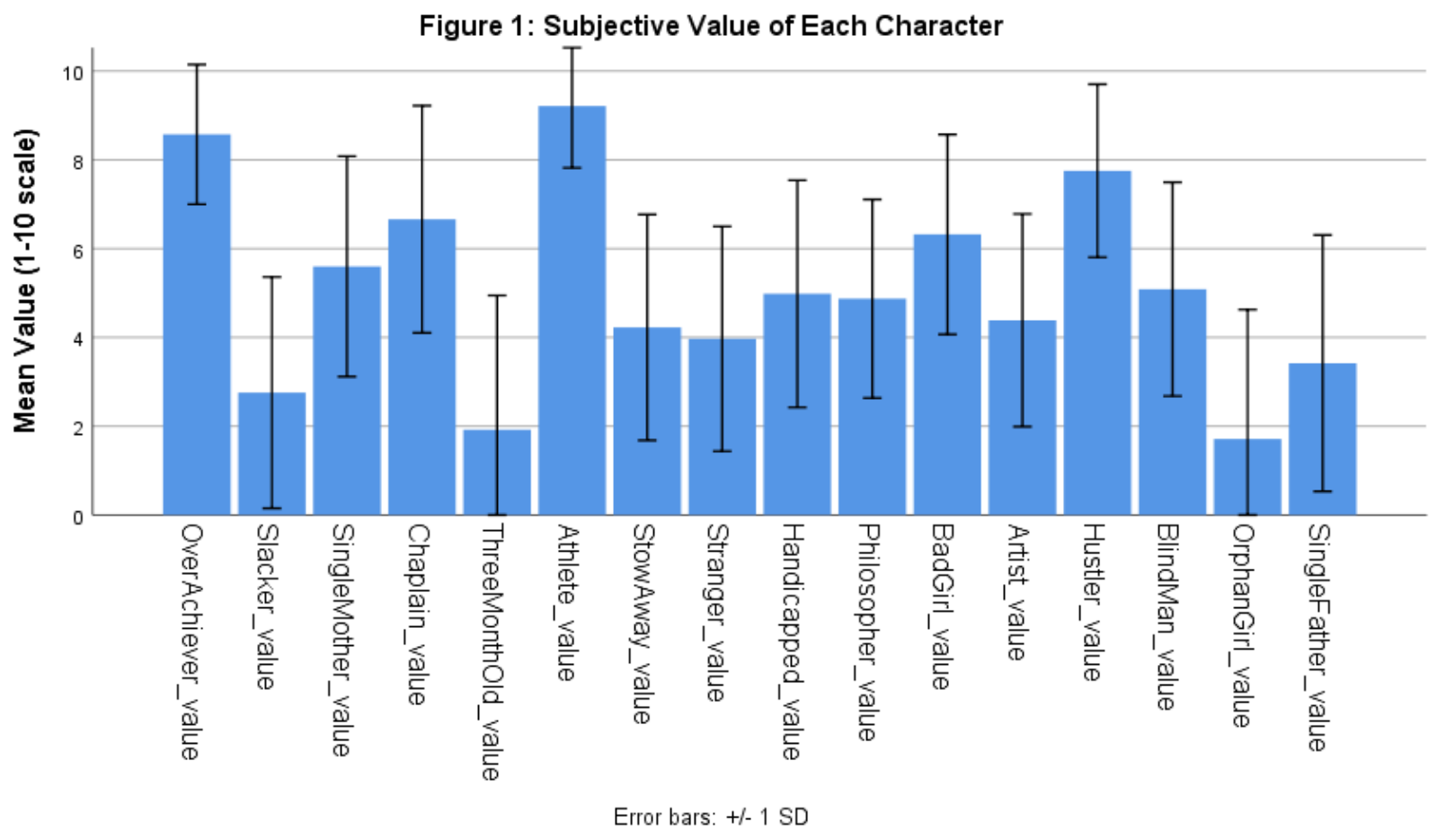

Students' discrimination among these characters is well established. Not only do the mean scores vary dramatically and in ways that are intuitive (helpless children score low, others with skills and spare work hours score high), the standard deviations are low. Thirteen of these 16 sets of scores show standard deviations of less than 2.8. Hence, there is widespread agreement on how valuable most of these characters are to the group. Sets of scores for only three characters have higher standard deviations. These include the two helpless children (S.D. = 2.9 and 3, respectively) and the Single Father (S.D. = 2.9), who is a potentially dangerous character. This high degree of discrimination indicates that students are indeed doing the preliminary work of thinking carefully about characters' worth, which positions them later make reasoned decisions about how to share available work hours.

This allocation of spare hours is the central challenge of the simulation. While most students in the graded condition share the 29 daily person-hours in such a way as to allow nearly all of the characters to make approximately even progress toward the 200 hours required to earn 
a spot on the boat, there is, of course, variation on the allocation strategies. A few of the characters are more frequently left without help than the others. As one would expect, students in the ungraded condition share much less equally than do those with a grade at stake. Table 1 shows an overview of students' responses to the characters in both of the conditions.

Table 1

\section{Participants' Allocation of Spare Work Hours}

\begin{tabular}{|c|c|c|c|c|c|c|}
\hline Character & $\begin{array}{l}\text { Average \# } \\
\text { of hours } \\
\text { shared (w/ } \\
\text { grade at } \\
\text { stake) }\end{array}$ & $\begin{array}{l}\text { Average \# } \\
\text { of hours } \\
\text { shared (w/o } \\
\text { grade at } \\
\text { stake) }\end{array}$ & $\begin{array}{l}\text { Difference in } \\
\text { \# of hours } \\
\text { shared (grade } \\
\text { minus no } \\
\text { grade) }\end{array}$ & $\begin{array}{l}\% \text { who } \\
\text { withheld } \\
\text { all hours } \\
\text { from this } \\
\text { character } \\
\text { (w/ grade } \\
\text { at stake) }\end{array}$ & $\begin{array}{l}\% \text { who } \\
\text { withheld } \\
\text { all hours } \\
\text { from this } \\
\text { character } \\
\text { (w/o a } \\
\text { grade at } \\
\text { stake) }\end{array}$ & $\begin{array}{l}\text { Bi-variate } \\
\text { relationship } \\
\text { between value } \\
\text { and hours } \\
\text { shared (all } \\
\text { respondents) }\end{array}$ \\
\hline The Slacker * & 1 & .6 & .4 & $20.6 \%$ & $55.8 \%$ & $.408 *$ \\
\hline The Single Father & 1.07 & .88 & .19 & $18.4 \%$ & $46.2 \%$ & $.384 *$ \\
\hline The Chaplain & 1.47 & 1.54 & -.07 & $4.3 \%$ & $30.8 \%$ & $.33 *$ \\
\hline The Orphan Girl * & 3.75 & 2.26 & 1.49 & $24.1 \%$ & $51.9 \%$ & $.272 *$ \\
\hline The Artist $*$ & 1.24 & .89 & .35 & $9.2 \%$ & $36.5 \%$ & $.253 *$ \\
\hline The Stranger * & 1.28 & .89 & .39 & $7.8 \%$ & $38.5 \%$ & $.252 *$ \\
\hline $\begin{array}{l}\text { The Handicapped } \\
\text { Person }\end{array}$ & 1.45 & 1.47 & -.02 & $6.4 \%$ & $26.9 \%$ & $.243^{*}$ \\
\hline $\begin{array}{l}\text { The 3-Month-Old } \\
\text { Male Child * }\end{array}$ & 3.89 & 2.4 & 1.49 & $18.7 \%$ & $48.1 \%$ & $.219 *$ \\
\hline The Blind Man & 1.42 & 1.51 & -.09 & $6.4 \%$ & $28.8 \%$ & $.222 *$ \\
\hline $\begin{array}{l}\text { The Stow-Away } \\
\text { Kid }\end{array}$ & 1.32 & 1.56 & -.24 & $9.2 \%$ & $34.6 \%$ & $.204 *$ \\
\hline The Bad Girl & 1.54 & 1.72 & -.18 & $1.4 \%$ & $11.5 \%$ & .116 \\
\hline The Philosopher & 1.24 & 1.15 & .09 & $7.8 \%$ & $30.8 \%$ & .086 \\
\hline The Single Mother & 1.78 & 1.8 & -.02 & $2.8 \%$ & $13.5 \%$ & .069 \\
\hline $\begin{array}{l}\text { The Over- } \\
\text { Achiever } *\end{array}$ & 1.83 & 3.1 & -1.27 & $3.5 \%$ & $7.7 \%$ & .043 \\
\hline The Hustler * & 1.94 & 3.61 & -1.67 & $1.4 \%$ & $5.8 \%$ & .012 \\
\hline The Athlete * & 2.06 & 3.88 & -1.62 & $2.8 \%$ & $7.7 \%$ & -.036 \\
\hline
\end{tabular}

Note: Correlations in the right-most column are based on 193 students. The asterisk next to the character name indicates that ANOVA reveals significantly different patterns of variance across the two conditions.

Comparing students across the two conditions, the chief difference is that those in the control group were more willing to take risks, that is, to act in less of a Rawlsian way in withholding help from the less desirable characters. For instance, among the students in the graded condition, no more than $25 \%$ of them withheld help from even the least desirable characters. In sharp contrast, students in the ungraded condition withheld all help from 11 of the 
characters $25 \%$ or more of the time, and this figure exceeded $35 \%$ for six of the characters. Fully $56 \%$ of the students in the ungraded group withheld all help from the Slacker. (Apparently being lazy and a sexual predator doesn't help his reputation.) These different strategies occur despite both groups of students subjectively valuing the characters in very similar ways.

Examining the means and standard deviations of the scores across conditions further illustrates the difference a grade makes. Students in the ungraded condition shared significantly more hours with eight of the 16 characters when compared to the students in the graded condition. Not surprisingly, the standard deviations differed on these same eight sets of character scores. When students differed from their peers in the graded condition, the students in the ungraded condition offered more dispersed scores in the way they shared hours. Not having a grade on the line clearly though not overwhelmingly leads students to take more chances. This leads to the conclusion that if one wants students to take this exercise seriously, one would want to attach a grade to the students' performance in some way. It would not have to be accomplished in the same way as done here, but some means of individual accountability appears essential.

Pooling all students across both conditions, there emerges a clear correspondence between the two groups of students revealing that the poorly valued characters are somewhat punished when it comes to the number of work hours shared. These lower-value characters are left without any help at all at significantly higher rates than are the higher-value characters, and the correlation between the subjective valuation and the number of hours shared is stronger among the less-liked characters than among the more-liked characters. This reveals that for the least-valued adult characters, such as the Slacker and the Single Father, the undesirability of these characters overrode the caution students displayed in dealing with the other characters, even to the point of risking the chance that they would not be this character. Table 1 above lists the characters in the order of the strength of this correlation. The rest of this paper focuses on those students who performed the simulation for a grade.

\section{Focusing on Decisions by Students in the Graded Condition}

Although the characters varied considerably in how students subjectively rated their value to the group - from an average of about two for the Three Month Old to about nine for the Athlete - when it came to decisions about sharing work hours these differences were 
dramatically smaller. Figure 2 shows the average number of hours shared for each character, along with error bars showing one standard deviation.

Figure 2: Average \# of Hours Shared, by Character

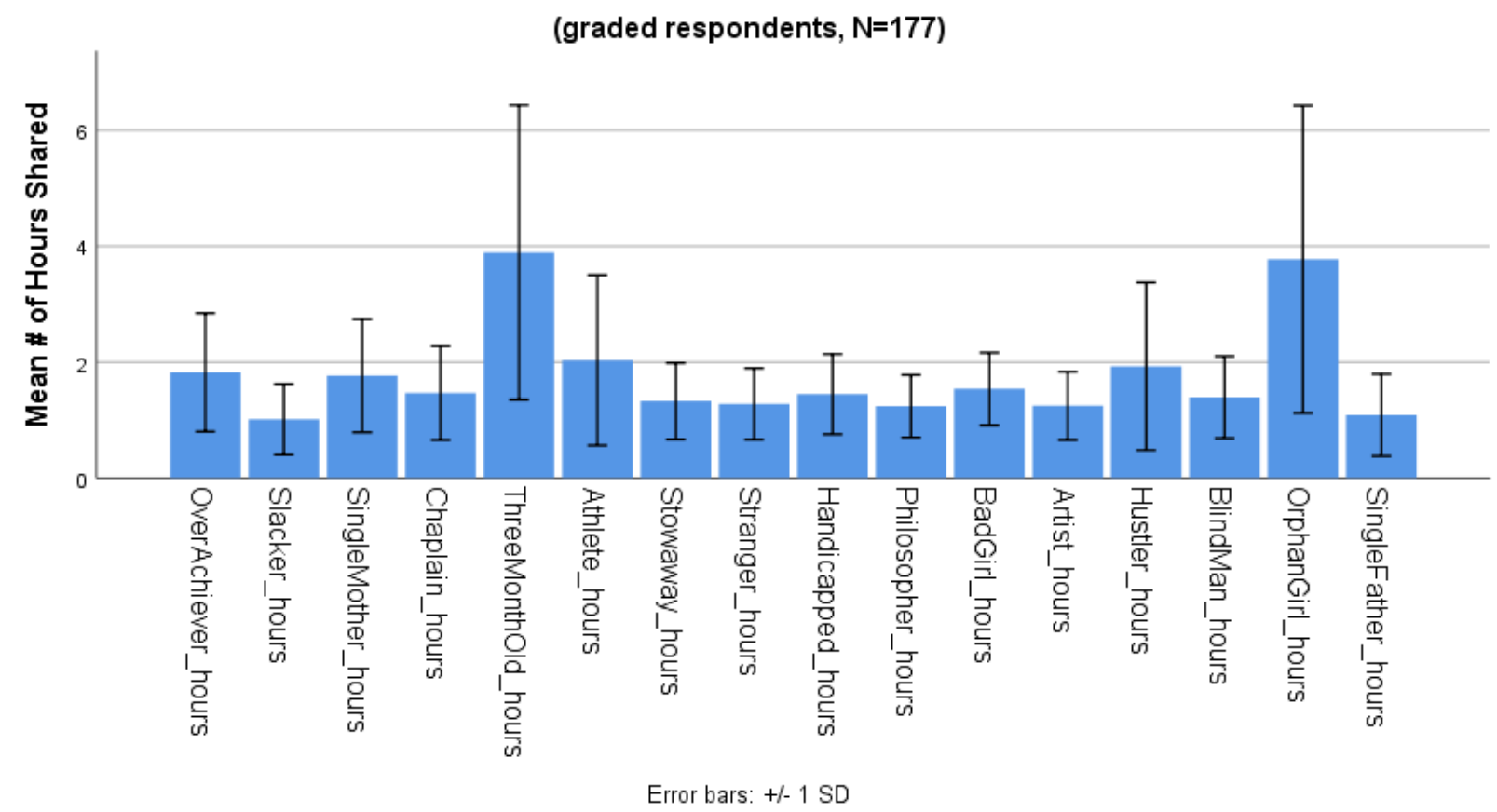

The evidence here shows that when students who have a grade at stake consider the risk of not helping any given character, they act in substantially, though not entirely, Rawlsian ways. Specifically, the large majority of them provide a minimum floor or support for nearly all of the characters. For the least desirable characters, only one-fifth to one-quarter of students leave them without help (which means that such a character, with the exception of the helpless children, will survive but never get off of the island). Considering all 16 characters, the average character is left without help by only $9.05 \%$ of students in the graded condition.

Recalling that Rawls did not assume that people behind a veil of ignorance would institute an egalitarian society he did, however, posit that people situated this way would look out for the most vulnerable among them (consider the difference principal, Rawls 1971, pp. 7680). Specifically, Rawls' expected that they would allow for economic differences so long as such differences would be to everyone's advantage, including the least well off. While this crucial claim is well borne out for the large majority of the characters in this simulation, the two helpless children, intentionally designed in order to test students' willingness to redistribute vital 
resources when doing so is quite costly, would not survive. Even if we limit the analysis to those students who were willing to share some (non-zero) number of hours with these children, the average number of hours shared is still slightly less than that required for survival (4.78 hours for the Three Month Old Male Child, and 4.95 for the Orphan Girl, both short of the five hours required to survive). This stands as a significant qualifier to the larger pattern of the group looking out for weak members, and it fits with the patterns found in the empirical tests of Rawls discussed above, indicating that the difference principle does not tend to be robustly instituted by experimental subjects. With these two child characters and among these students, charity has found its limits. In contrast, even the potentially dangerous Single Father - a character designed to engender animosity - is granted just over one hour per day on average, allowing him to eventually earn a spot on a boat.

A stronger claim about equality is not well supported by the evidence. If the expectation were that students would distribute the spare work hours so as to equalize everyone's progress toward securing a place on the boat, we would expect to see a specific pattern in students' responses. They would first award five hours toward each of the helpless children, to bring them up to the survival point, and then equally divide the remaining 19 hours across all of the characters. ${ }^{3}$ This would result in the two children receiving 6.1875 hours and every other character receiving 1.1875 hours per day. In reality, the two helpless children have been shortshrifted by being given, on average, only 3.89 hours (for the Three-Month-Old Male Child) and 3.75 hours (the Orphan Girl), or only about $60 \%$ of what an equal outcome would look like. The remaining 14 characters in reality have received between $84 \%$ and $173 \%$ of what equality would involve. Eight of the 16 were given resources within $20 \%$ of this threshold. Four of the characters were given $150 \%$ or more. Figure 3 shows the actual number of hours shared expressed as a proportion of the number of hours that would have been shared under an equal outcome arrangement.

\footnotetext{
${ }^{3}$ Several years ago a student hit on a clever way to optimize the speed of getting everyone off the island by building multiple boats. Her strategy was to first ship off the weak characters, then build a second boat for the remainder. I have since prohibited this strategy because it reduces the cost of sharing spare work hours with the needy characters, and in doing this limits the power of the simulation.
} 
Figure 3: Actual Hours Shared Compared to Hypothetical under an Equal Sharing Arrangement

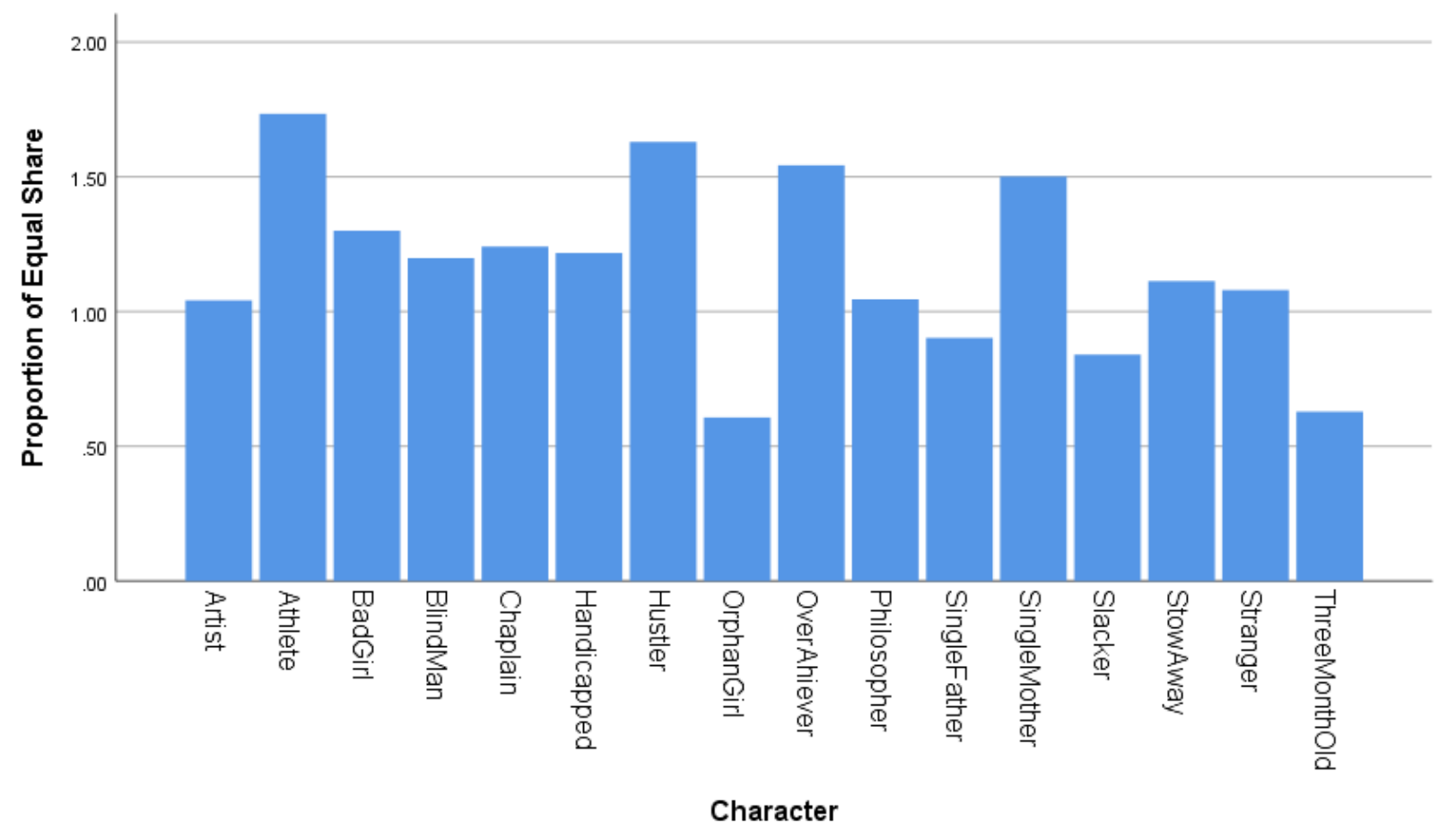

In sum, students are willing to support nearly all of the characters, despite their varied limitations. The Handicapped Person cannot swim, walk, or carry loads. The Philosopher cannot climb trees to harvest fruit. The Hustler seems to be a thief. The Slacker has a record of sexual aggression. The Artist is pleasant but essentially bereft of island skills. Students also showed a significant willingness to redistribute work hours from those who have ample to spare, including Over-Achiever and the Athlete. If translated into a tax code, the level of redistribution typically called for by students' responses in the simulation would be considered confiscatory, thus would likely run into stiff political resistance. However, students seem comfortable with this level of redistribution, given the structure of the simulation. The one significant limitation for a thoroughgoing Rawlsian understanding of students' choices is that the two helpless children are, on average, not allocated quite enough hours to survive. For them the cost of receiving a place on a boat is a bit too steep for most students.

One final observation arises from the quantitative side of this project. Male and female students approach this simulation in ways that are nearly indistinguishable. Among students in the graded condition, gender correlates significantly but weakly (Pearson correlations less than 
.17) with the subjective values assigned to only four of the characters: the Single Mother (who is the mother of the Three Month Old Male Child), the Stranger (who is 11 years old), the Chaplain (who is an 80-year old woman), and the Blind Man. Arguably, these are some of the characters women would particularly identify with, though this list omits, for instance, the Orphan Girl. Note that the Orphan Girl is described as not having a pleasant disposition. When it comes to distributing resources, gender does not correlate with the number of work hours allocated to any of the characters in either the graded or the non-graded condition. Whatever one might think about female respondents potentially sympathizing more strongly with a range of characters, such relationships are weak to non-existent.

\section{Other Responses to the Simulation and Accompanying Insights}

Other interesting findings have emerged from this simulation over the years. While this part of the discussion is necessarily subjective, and others might have different experiences in their own classrooms based on this simulation, my students have found it useful to contemplate these issues and apply these insights to our discussion of American social policy.

First, prior to working through this simulation and seeing how they themselves and hundreds of their peers have responded, many students had not considered in any depth the ways in which their upbringings, economic status, and social connections condition their perspectives on social policy. While it is not possible to determine precisely how transformative this experience is for the average student, participants in my class hear echoes of the desert island exercise throughout a typical semester. I raise these insights, as do the students. For example, when, as a preface to our unit on affirmative action, students compile a personal inventory of meaningful opportunities they have enjoyed not because of merit but rather because of a social connection, such as family or friends, students readily generate long lists. They talk about jobs they secured because the employer is a friend of the family. They reference internship experiences they secured because of a school teacher they know. They seem to have no difficulty acknowledging that the density and reach of their social networks speak directly to their opportunity sets. Of course, some students persistently cling to notions of just desert, relating stories of successes due to their own work effort, or of immigrant grandparents and rags to riches stories, no matter how atypical those accounts actually are (cf. research from the Pew Economic Mobility Project). 
Second, students develop an enhanced ability to talk about why they value certain kinds of people as they do. They are later able to explain why they like the Earned Income Tax Credit with its strong work requirement, or why they think as they do about race-based affirmative action in college admissions. They acknowledge the connections between background experiences and privileges, or lack thereof, and how this enables, or limits, individuals' abilities to engage either in self-help or to advance group projects. This said, as they talk about reasons for valuing one type of individual over another they are, implicitly or explicitly, still sorting people into categories of more versus less worthy, a distinction that has been part of the American welfare discourse since colonial times (Katz 1986). For my part, the goal is to invite students to think more in terms of skills and less in terms of personal or moral failings, but this is, naturally, somewhat beyond the reach of what we can do in the classroom over one semester.

Third, strongly market-oriented students often struggle with this simulation. Their tendency to believe in meritocracy and just deserts runs head-long into the pattern of student responses, and in most cases their own responses. Viewing data from hundreds of students over previous semesters that shows broad patterns of near-Rawlsian behavior often does little to change their minds about how self-knowledge colors one's policy choices and about deservingness more generally (once they are no longer stuck behind a veil of ignorance). Of course, there is a fine balance to be struck between having students experience a veil of ignorance-like situation that consistently produces these kinds of outcomes, on one hand, and preaching from their professor, on the other.

Fourth, the pattern of decisions about helping the moderately poorly resourced characters while tending to neglect the least well off helpless children mimics how the safety net in the United States treats, for instance, the working poor versus the homeless. The former stand to benefit from programs such as the Earned Income Tax Credit, the Low Income Home Energy Assistance Program, subsidized housing, and other supports. The latter receive quite a bit less, on the whole. This rough parallel between outcomes on the desert island and outcomes among America's very poor is not lost on the students.

Over the years a few complaints have emerged with regularity. The most common response comes from those students who argue that this simulation is not realistic and that in the "real world" they would behave differently, specifically that they would withhold help from 
uncooperative characters. By the "real world" they generally mean one in which they possess self-knowledge, including an awareness of their resources, privileges, and limitations. Of course, it is difficult to know how seriously to take students who, perhaps (or perhaps not?) flippantly, discuss banishing or even killing undesirable characters if they were to find themselves in such a dire situation. My effort to point out that this exercise with its grade stake is in fact quite real sometimes carries very little water with students who are determined to challenge me. Be this as it may, it is apparent that this complaint reinforces the insight that self-knowledge strongly conditions how people express choices over redistributive public policies and that these students simply cannot bring themselves to grasp this as fully as they might.

Another complaint that surfaces with some regularly references the impossibility of ensuring, through one's efforts, that one can earn anything above a $90 \%$ on this activity. This is true, and it goes against the rest of my grading practices. However, I believe the lessons to be learned through this exercise are worth the loss of a small measure of control over one's grade. The $.3 \%$ difference in their overall course grade that results from earning a $90 \%$ versus a $100 \%$ on this activity is, I think, worth the lessons learned. I also often curve the final grade distribution by a percentage point or so, meaning that this tiny bit of difference comes out in the wash.

\section{Considerations on Improvements}

The decisions students make in this simulation highlight how knowledge of one's social situation powerfully shapes one's choices for redistribution, and how ignorance induces the large majority of students to share more than they would in their ordinary lives, where they remain quite aware of their own privileges and disadvantages. The availability of longitudinal data from this simulation allows students to see not only how much sharing their particular cohort engages in but also how this pattern is typical of previous cohorts. All of this serves to make our class conversations about social policy and redistribution more interesting as they compare and contrast their behavior among the shipwrecked with their stated preferences for certain public policies in the contemporary American context.

Students and colleagues have suggested various ideas for revisions over the years. In the interest of developing a longitudinal data set, I have thus far declined to implement any that 
would fundamentally alter the structure of the simulation. However, a couple of ideas seem worth considering. First, the deficits faced by the two helpless children are severe. Requiring five hours of care per day makes ensuring their survival truly costly to the group. Potentially a revised simulation could either eliminate one of these children or render them less of a burden by making them more self-sufficient. Having a character who faces, for instance, a two-hour per day deficit could tempt students to allocate sufficient resources to ensure a place on the boat for this character. As written, the two helpless children certainly establish a low baseline, and this serves a purpose, but to have two of them in such dire straits is probably more than what is needed to establish this baseline reference point. It might be useful to maintain only one of the needy children and change the other into a character in a little less need in order to probe the willingness of students to help a character who has a deficit of, say, two hours.

Second, it is possible that the large number of characters encourages students to take chances by banishing one or two of them, knowing the odds are still good that no character they banish is likely to be their own. If there were, for instance, only 8 or 10 characters, students would probably become more risk-averse than they already are. On the other hand, the finding that students look out for 14 of the 16 characters itself makes a point: that behind a veil of ignorance students will generally, though not perfectly, act as Rawls supposed rational people would.

Despite the limitations noted here, this simulation has worked well as an ice-breaker for new students in my class, it has led many students to reflect on how self-knowledge shapes policy positions, and it has provided a touchstone that is quite useful for leveraging more penetrating discussions about social policy. The repeated pattern over time of students sharing resources with nearly all of the characters, though not quite in egalitarian ways, approximates what John Rawls had in mind in his famous project involving an original position and a veil of ignorance. The decisions of students to not allocate sufficient resources for the two young children remains an exception to the broader pattern of protecting the most vulnerable. This too has helped drive classroom conversations about difficult-to-help populations, such as individuals on public assistance who have multiple barriers to work. 
The full text of this simulation is available from the author. I would appreciate hearing your stories of how this project - either in its present form or modified to fit your local needs works with your students. 


\section{Appendix}

The following is a set of excerpts from the description of the desert island conditions and the assignment. The character descriptions appear below.

“... Your group was able to salvage a few things from the ship before it sank: a few tools ... and about a week's worth of food. The group was not able to bring ashore any matches. Once this food runs out, you'll have to figure out how to feed yourself, or you will, over the next few weeks, slowly starve to death. ... Because of varying skill levels and differences in physical strength, the number of hours each person will need to spend working each day in order to minimally survive varies. Some members of the group are more productive workers than others. The strongest/most skilled need to work 7 hours each day in order to survive. The least skilled will need to work for up to 17 hours each day in order to survive. Performing less than one's minimum number of hours of work will, within a very few weeks, lead to life-threatening conditions, such as exposure and starvation, at least for that person, and potentially for others in the group. Assume that the average person can get by on 7 hours of sleep at night (you'll likely be tired at the end of a typical day). The strongest/most skilled people will have up to 9 hours of spare time each day. The weakest/least skilled people will have no spare time; they will need to work every waking hour of the day in order to survive. For those who have it, spare time can either be used to rest, pursue hobbies or other projects (like building a boat), or to trade with others whose help one may need (i.e., to gather food, water, etc.). Spare hours may also be given away to others who need or want the help. Each person will have to decide on his/her own what to do with one's own spare hours. ... One essential project to pursue in spare time is to build a boat that could take you away from the island. Building such a boat would require 200 hours of work per passenger that the boat could be expected to convey. (You could build a one-person boat in 200 person-hours of work, a two-person boat in 400 person-hours, a three-person boat in 600 person-hours, and so on, up to 3,200 person-hours of work to build a boat that will carry all 16 people). Several members of the group have already expressed interest in giving the boat project a try. For the purposes of this simulation, you can build only one boat. A core part of this project is to earn a grade on how quickly your character can accumulate the required number of hours to complete her/his spot on a boat. ... There is no law on these islands apart from what individuals, acting alone or collectively, decide. Some of the others on the island have physical limitations, and others have, shall we say, troubling personality characteristics. Some sharing or teamwork will be necessary for most of these characters, since few of them individually possess all of the skills needed for survival. You'll have to figure out for yourself the extent to which these assets and negatives warrant cooperation. At this early stage, no one knows which role he/she will play. You'll learn

that later. ....You will earn a real grade for this assignment that reflects how well your character fares under the rules that you set out. The catch, of course, is that your character will have to thrive (or not), live (or die) under the rules that you establish prior to learning which character is yours. You're facing a gamble here, and the stakes involve $3 \%$ of your overall course grade. By the time you read this, Greg will have already assigned roles randomly, and you will learn which character is yours during a later class meeting. You should assume that each of the roles described below will be represented at least once among the students in our class this semester. You are, as John Rawls would say, behind a veil of ignorance. (See the reading by Michael Sandel on Rawls.) Sending one or a few characters out on a boat in order to bring back help is not permitted. Once a character has left the island, that character's resources or deficits no longer apply to the remaining group. ..." 


\section{The Over-Achiever}

The over-achiever is multi-talented, mechanically inclined, healthy, and resourceful, even if she a real weakling in one respect. She can figure out how to build a wide variety of useful - indeed, life-saving things, including starting fires and swimming long distances. However, she has a medical condition that makes her super-sensitive to prolonged sunlight. She sunburns very easily, and even moderate sunburns are debilitating. She needs to spend almost all of her time in the shade. She is 40 years old. She needs to work 11 hours a day to survive. \{6 spare hours\}

\section{The Artist}

The artist can carve the most exquisite coconut shells that anyone has ever seen. His art work is so stunningly beautiful that people can sit and admire is for hours. Unfortunately, he has very few other skills relevant to island life. In a more general sense, he is mechanically inept, so he's not very good at building things. The artist also has a debilitating fear of heights, so climbing high trees is out of the question. He can swim only short distances. He is somewhat clumsy, thus an ineffective hunter. He can carry water. Because of a moderately serious case of diabetes, you must east a reasonably good diet every day in order to avoid going into hypoglycemic shock, which would kill him. On the bright side, he's an amazing story-teller. In the evenings he can sit around the fire (which someone else will have to start, since he doesn't know how) and weave wonderful tales that entertain the others and that help them forget the day's problems. The artist is 45 years old and needs to work 17 hours a day to survive. \{no spare hours\}

\section{The Athlete}

She is perhaps the most talented person on the island. She can hunt, climb trees, carry water, and swim long distances if necessary. She is potentially friendly, but she had a fist fight on board the ship with the Slacker before the boat went down. One other down side she suffers is that she is mechanically inept. She often cuts herself when trying to work with sharp objects. She has never been able to figure out how to start fires. The Athlete is 20 years old. She needs to work 8 hours a day to survive. $\{9$ spare hours\}

\section{The Slacker}

Whether or not the Slacker has talents that could help the group isn't clear. He seems to be of average physical strength, though he suffered a broken foot in escaping the sinking ship. It looks like it's going to heal, but you'll need a couple of months before he can do any meaningful work. He is otherwise in reasonably good health, aside from the black eye that the Athlete gave him during that fist fight on the ship. What is clear is that the only kind of hunting he wants to do involves the pursuit of good looking members of the group. He was accused of sexually harassing another passenger on the ship, though we'll never get to the bottom of that, since that person went to the bottom of the sea with the ship. It's been rumored that the only reason he is going to climb any trees (once the foot heals in a couple of months) is to go after fruit in order to improve his chances of striking up a romance with a group member that he's had his eye on for a while. The Slacker is fairly sure that in time others will find food 
and will cut him in on a share of it, if he can just get them to notice what a magnetic personality he has. He is 18 years old and needs to work 17 hours a day to survive. \{no spare hours\}

\section{The Handicapped Person}

The Handicapped Person is a 60-year old female who cannot walk, swim, or carry loads. She has to crawl everywhere she goes. It's a miracle she didn't drown when the ship sank. Her hands still work, so she can help make useful tools, and she's the best tailor among the group. She has a wonderful personality, and most people seem to enjoy being around her. She's a great story teller, able to relieve the group of their woes, even if for a little while. Many members of the group would love to sit around the fire at night listening to her tales. Too bad she doesn't have more free time to do that - she needs to work 17 hours a day to survive. \{no spare hours\}

\section{The Philosopher}

Before that ship sank he was a highly regarded philosopher and author of a dozen books. Now he finds himself completely out of his element, and because he grew up in a family with hired help he barely knows how to change a light bulb, much less build a raft or a shelter. To complicate matters, he lost a hand in an auto accident years ago (had a little too much to drink). He's intelligent, so he could learn skills relevant to island life, but that might take a while. Who knows? The Philosopher has always been very limited physically. He can't climb trees or fetch water from the springs because he has only one hand, but he can swim short distances (slowly) and has expressed interest in learning how to hunt (again, this might take a while). Given the challenges, his attitude is clearly negative toward this whole experience. On the positive side, he is the only person on your ill-fated ship who speaks both English and Navajo. The Philosopher is 50 years old. He needs to work 17 hours a day to survive. \{no spare hours\}

\section{The Bad Girl}

What she was doing on that ship in the first place is mystery. She doesn't like these people, and she certainly doesn't like camping. Getting ashore without drowning was no problem, since she is a great swimmer. She is of average physical strength and agility, so she can hunt a little, climb trees, and carry water. However, drug abuse has led to a clinically diagnosed case of paranoia. In the past, she has reacted violently to people who challenge or criticize her. She might be able to overcome this condition in time, but this would require a lot of patience and hard work on her and the shipmates' parts. She is 22 years old and needs to work 14 hours a day to survive. \{3 spare hours\}

\section{The Stranger}

The Stranger is an 11 year-old Navajo boy who speaks no languages other than his own. He has very few skills relevant to island life. He doesn't know how to hunt, fish, or swim. He can't run very fast because of an early childhood injury, so chasing down wild game really isn't an option for him. He is clumsy, so when he tries to carry water he usually spills most of it, but he is willing to work hard and to carry what he can. The Stranger is mechanically incompetent, but he could potentially help if he could follow others' directions (too bad he can't understand their language). He is suspicious of this newly arrived group of castaways, and some of them are suspicious of him. The one-week food supply he came ashore with just ran out. He's getting hungry, and he needs to work 17 hours a day to survive. \{no spare hours\}

\section{The Single Mother}

The Single Mother has a 3 month-old male child with her whose care will require 5 hours each day if it is to survive. The Single mother became a single-parent by choice before the ship wreck. She suffers from 
early onset arthritis in her hands, so carrying loads is extremely painful, and climbing trees would be dangerous and painful. She doesn't have many island relevant skills, but she's a quick learner and willing to try new things. Fortunately, she's a great swimmer and can make it to the other islands and back. She is 25 years old. She needs to work 15 hours a day to keep herself alive ( 2 spare hours), but the baby boy needs 5 hours of care, so if the Single Mother continues to act as the infant's caretaker (not necessarily the case) the Single Mother is now 3 hours in the hole.

\section{The 3-month-Old Male Child}

The child of the Single Mother. See above. Needs 5 hours of care per day to survive. Without 5 hours of care per day, he will die within two weeks. Seems to have a charming disposition. $\{5$ hour deficit\}

\section{The Orphan Girl}

The Orphan Girl is a 1 year old, now an orphan because her father died when the ship went down. She's clearly in need of significant help if she is to survive. She can't work at all and will require 5 hours of work each day from others if she is to survive. Without 5 hours of care per day, she will die within two weeks. Does not seem to have charming disposition. $\{5$ hour deficit $\}$

\section{The Stow-Away Kid}

Brave for a 9 year old, he stowed away on this ill-fated ship only to be discovered mid-voyage by the captain. The two of them got into a fight, and the captain broke the Stow-Away's right (dominant) arm. Within a couple of months the arm will heal, but until then he is unable to carry water, hunt or climb trees. Once he heals he will be of average ability in these areas. He's a weak swimmer, but once healed he'll be able to cover distances of up to $1 / 2$ mile. He needs to work 17 hours a day to survive. \{no spare hours\}

\section{The Chaplain}

At 80, the Chaplain is the oldest one on the island, but her accumulated wisdom may do some good for the group. She has 40 years of experience as a chaplain with an emphasis on dispute mediation. She also has substantial experience in psychological and spiritual counseling. She is one of the few on the island who can start fires without matches. Unfortunately, she can't climb trees, or hunt or carry water effectively. She can swim only short distances. She also has substantial training in medicine and is the closest thing the group has to a physician. She alone knows how to navigate by the stars. She needs to work 17 hours a day to survive. \{no spare hours\}

\section{The Hustler}

The Hustler is a 25 year old female who has a track record as a thief and a cheat. She's talented and in pretty good physical condition and can swim up to $1 / 2$ mile at a stretch. Back on the ship she was accused by several people (including the Slacker and the Bad Girl) of stealing food and money from others. She can climb trees, start fires, and hunt, but there may be lingering ill will between her and other members of your group. Maybe she can work this out in a good way ... who knows? She will have to work 8 hours a day to survive. $\{9$ spare hours $\}$

\section{The Blind Man}

He is 55 years old and completely blind. What's more, he suffers from significant arthritis as a result of having fought bravely in two wars before retiring from the military as a highly decorated soldier. His 
arthritis limits the work he can do to light-duty jobs only. Because he's blind, he can't fetch water, nor are his tree-climbing abilities useful. However, he can swim short distances, and, interestingly enough, can build small animal traps if someone will bring him materials. He has exhibited a strong sense of right and wrong and has shown a very low tolerance of foolishness or immorality by others. Island life might change his attitudes, but then again, it can be hard to teach old dogs new tricks. He has to work 17 hours a day to survive. \{no spare hours\}

\section{The Single Father}

The Single Father is 30 years old and a recent prison escapee, where he was serving a 50 -year term for murder of his grandmother. On his way to the ill-fated ship ride, he kidnapped his 3-year-old daughter from her mother (his ex-wife, whom he threatened with death during the kidnapping because of the way he thinks she had been talking about him). He's a person of considerable determination and is a good swimmer. He has a seriously negative attitude toward several of the others from the ship. The stash of heroin he has may help him take the edge off that negativity, at least until it runs out. To meet his needs, the Single Father needs to work 17 hours a day. \{no spare hours\}

This chart shows how the duration of boat building is converted into a grade:

\begin{tabular}{|l|l|}
\hline $\begin{array}{l}\text { Number of days required to } \\
\text { accumulate } 200 \text { hours of work } \\
\text { on the boat }\end{array}$ & $\begin{array}{l}\text { Grade on this assignment, } \\
\text { expressed as a percentage }\end{array}$ \\
\hline Fewer than 40 days & $105 \%$ \\
\hline $40-52$ & 102 \\
\hline $53-65$ & 100 \\
\hline $66-79$ & 98 \\
\hline $80-92$ & 96 \\
\hline $93-105$ & 95 \\
\hline $106-118$ & 94 \\
\hline $119-131$ & 93 \\
\hline $132-144$ & 92 \\
\hline $145-157$ & 91 \\
\hline $158-170$ & 90 \\
\hline $171-183$ & 85 \\
\hline $184-196$ & 80 \\
\hline $197-209$ & 75 \\
\hline $210-222$ & 70 \\
\hline $223-235$ & 65 \\
\hline $236-248$ & 60 \\
\hline $249-261$ & 55 \\
\hline $262-274$ & 50 \\
\hline $275-287$ & 45 \\
\hline $288-300$ & 40 \\
\hline $301-313$ & 35 \\
\hline $314-326$ & 30 \\
\hline $327-339$ & 25 \\
\hline & \\
\hline
\end{tabular}


Alive but stuck on the island for 20

more than 339 days

The death of your character 


\section{Sources}

Bond, Doug, and Jong-Chul Park. 1991. “An Empirical Test of Rawls's Theory of Justice: A Second Approach, in Korea and the United States," Simulation and Gaming 22 (4): 44362.

Chan, Ho Mun. 2005. "Rawls' Theory of Justice: A Naturalistic Evaluation," Journal of Medicine and Philosophy 30 (5): 449-65

Elster, Jon. 1983. Sour Grapes: Studies in the Subversion of Rationality. New York: Cambridge University Press.

Frohlich, Norman, Joe Oppenheimer, and Cheryl Eavey. 1987. "Choices of Principles of Distributive Justice in Experimental Groups," American Journal of Political Science 31: 606-36.

Kukathas, Chandran, and Philip Pettit. 1990. Rawls: A Theory of Justice and Its Critics. Stanford: Stanford University Press.

Katz, Michael. 1986. In the Shadow of the Poorhouse. New York: Basic Books.

Nozick, Robert. 1974. Anarchy, State, and Utopia. New York: Basic Books.

Okin, Susan Moller. 1989. Justice, Gender, and the Family. New York: Basic Books.

Rawls, John. 1971. A Theory of Justice. Cambridge, MA: Harvard University Press.

Rawls, John. 1993. Political Liberalism. New York: Columbia University Press.

Rawls, John. 2001. Justice as Fairness: A Restatement. Cambridge, MA: Harvard University Press.

Sandel, Michael. 1998. Liberalism and the Limits of Justice, $2^{\text {nd }}$ edition. New York: Cambridge University Press.

Sandel, Michael. 2009. Justice: What's the Right Thing to Do? New York: Farrar, Straus and Giroux.

Sen, Amartya. 1992. Inequality Reexamined. New York: Russell Sage Foundation.

Walzer, Michael. 1983. Spheres of Justice: A Defense of Pluralism and Equality. New York: Basic Books. 
Wolff, Robert. 1977. Understanding Rawls: A Reconstruction and Critique of A Theory of Justice. Princeton: Princeton University Press. 